\title{
Prediction and Classification of Financial Criteria of Management Control System in Manufactories Using Deep Interaction Neural Network (DINN) and Machine Learning
}

\author{
Amir Yousefpour (iD) and Hamid Mazidabadi Farahani \\ School of Civil Engineering, Iran University of Science and Technology, Tehran, Iran \\ Correspondence should be addressed to Amir Yousefpour; amir_yousefpour@cmps2.iust.ac.ir
}

Received 6 September 2021; Accepted 27 December 2021; Published 27 February 2022

Academic Editor: Sameh S. Askar

Copyright ( $\odot 2022$ Amir Yousefpour and Hamid Mazidabadi Farahani. This is an open access article distributed under the Creative Commons Attribution License, which permits unrestricted use, distribution, and reproduction in any medium, provided the original work is properly cited.

\begin{abstract}
The management control system aids administrators in guiding a business toward its organizational plans; as a result, management control is primarily concerned with the execution of the plan and plans. Financial and nonfinancial criteria are used to create management control systems. The financial element focuses on net income, earnings, and other financial metrics. The two components of leadership strategy in this study are cost and differentiation, which highlight the strategy of differentiation in attaining higher quality due to the robust strategy's attention on a particular area of the company. In this study, we presented a novel method named deep interaction neural network to predict the performance of the manufacturing companies based on their leading competitors using features cost leadership and differentiation strategies. Moreover, the management control system is classified into two financial and nonfinancial factors based on machine learning methods. Based on the results, the presented factors can accurately estimate the company's performance based on management control criteria with a 93.48\% R-square. Moreover, it can be seen that the DT method is presented with higher classification performance values.
\end{abstract}

\section{Introduction}

Companies' procedures and processes to succeed in executing strategies are referred to as management control systems. Coherence, incentive, decision support, intended outcomes, assessment, and other management control systems are all aided by management control systems. In a broader sense, a management control system is intended to adjust the business to the operating area to protect partners' interests. To put it another way, the management control system's objective is to provide a secure network for delivering valuable data for decision-making, planning, and evaluation processes [1]. Like other functional units, this system is expected to interact with the scenarios of the external structure, which are referred to as features. As a result, one of the significant management policies is the management control system and its connection with considerations, particularly the type of corporate objectives [2].
Leadership and management control systems have been the subject of practical empirical studies globally since the early 1980s $[1,3,4]$. All such studies focused primarily only on financial report control systems. However, the study led by Merchant and Otley [1] progressively discovered the limitations of this strategy with the need to consider other control dimensions and eventually developed a control package that combined different control mechanisms. Businesses utilize a collection of linked control mechanisms to realign actions with strategic mission, by this viewpoint [5]. There are several methods for the application of machine learning, optimization, and programming in control systems [6-9]. These processes combine to produce the management control system. It is impossible to have a correct understanding of it without considering their connection and interaction. In recent decades, there has been a modest improvement in investigating the phenomena of "control" because of this fact and technique. However, most research 
linked to the design and construction of management control packages has focused solely on the efficacy of each control mechanism. For more than two decades, these processes have been ignored combined in many situations, such as the organization's strategy to attain successful control results after forming the closed approach. It has not yet been used perhaps and adequately in research. The management control system gathers and analyzes data to assess the performance of different business assets, such as personnel, technical, and financial resources, and the organization while taking organizational plans into account. Finally, the attitude of organizational resources to developing the conceptual framework is influenced by the management control system [10]. The management control system aids managers in guiding an organization toward its critical planning; as a result, management control is primarily concerned with the execution of the plan and plans $[11,12]$. Financial and nonfinancial factors are used to create management control systems. The financial element focuses on net income, earnings, and other financial metrics. Nevertheless, nonfinancial purposes such as quality products, customer happiness, sales involvement, timely submission, and staff ethics apply to all organizational subcategories. Based on financial and nonfinancial aspects, management control systems are divided into two subgroups. We introduced a unique approach called deep interaction neural network in this study to forecast the operating efficiency of firms based on their top rivals' cost leadership and differentiation tactics. Furthermore, using machine learning approaches, management control systems are divided into two groups depending on financial and nonfinancial aspects. The outcomes are shown in the following sections.

\section{Literature Review}

Malm and Brown [4] state that their approach is based on a survey of 40 years of control research. They present five control typologies that, together with the second structure, were given by Merchant and Van der Stede [13]; the most widely used control schema in academia [13]. Abadi et al. [14] have optimized the scheduling of nurses for the healthcare system [15]. Ahmadi et al. [15] have used a new model for selecting users with Q-reinforcement learning and machine learning methods [15]. Huang et al. [16] studied performance goals, community affiliation, and online collaboration ability to reflect connections. They for reach out to their destination using a deep learning method have used [16]. Wu et al. [17] have designed a new machine learning model for combining techniques to improve high-impact bug report forecasting [17]. He et al. [6] have analyzed multideep learning to classify users in the centric network [18]. Ahmadi et al. [19] and Taghizadech et al. [20] have designed a new model from machine learning that is regarding genetic algorithm for forecasting the GDP with ARDL bound test [19, 20]. Liu et al. [21] have analyzed an unsupervised approach for area flexibility in heterogeneous industries [21]. Dong et al. [22] have examined unsupervised feature training with learning aggregation-induced suitability vision [22]. Zhou et al. [23] have analyzed a new model for coding optimization. They have used a machine learning model in AVS2 [23]. Lv et al. [24] investigated spatial public goods games using PSO. The result shows that the proposed model has high accuracy [24]. Sharifi et al. [25] have studied the application of machine learning and digital style on control systems in the industry [25]. Ghorbani et al. [26] have analyzed risk hedging for call options in investments. Also, in another research, Ghorbani et al. [27] have studied on-call and put option pricing in investments [27]. Ahmadi [14] has evaluated a new economic growth model using a computational approach and fuzzy MCDM [14]. Prasad et al. [28] have used a surface technique and machine learning methods for methylene blue removal in the industry [28]. Ghorbani [29] has analyzed option pricing with investment using the random rate [29]. Korzeniowski et al. [30] have used put options using a linear programming for hull-white investment [30]. Zhang et al. [31] have investigated an optimization model for E-healthcare systems. The result shows that the proposed model is applied in the industry [31]. Ahmadi et al. [32] have studied a new hybrid approach for predicting GDP using machine learning approaches [32]. Artin et al. [33] have learned a new method for predicting traffic using ensemble learning and machine learning [33]. Merchant and Van der Stede [13] proposed a taxonomy of organizational control mechanisms that are based on the topic of administration and divide different forms of control into three fundamental classifications: (1) centers for financial responsibility, (2) incentive compensation mechanisms, and (3) financial management control methods, such as control of outcomes, activities, employees, and society, according to Merchant [2]. In human resources, behavioral outcomes such as work satisfaction have been critical. Some people consider providing a positive work activity to enhance employee welfare or job satisfaction to be a good aim in and of itself. Furthermore, it is reasonable to assume that employees who are content with their occupations would identify with organizational goals and perform more successfully, and all other factors are equal. Selfassessment procedures, in which employees offer an estimate of their performance or organizational unit across a range of potentially relevant management activities or goals, have dominated organizational outcomes in the contingencybased study [34]. More advanced technology, established operational processes, high levels of experts, and job norms were all part of administrative control. According to employers, employees were thought to have a high amount of authority and engagement in defining standards, and they spent more time budgeting [34] (see Table 1).

It is crucial to evaluate accounting information as part of a set of methods of control in order to describe how the financial report control system method conforms to the organizational framework of the company, one of the most significant of which is tactic; in those other words, it is supposed that companies, cash flows, and other control methods are meaningfully developed and built together [13]. Moradi et al. [44] investigated the influence of 
TABLe 1: Principles and a review of objective research for management control systems.

\begin{tabular}{|c|c|c|c|}
\hline $\begin{array}{l}\text { Management control } \\
\text { mechanisms }\end{array}$ & Definition & Relationships & Empirical evidence \\
\hline \multicolumn{4}{|l|}{ Financial control scheme } \\
\hline Diagnostic control & Observes events by looking for breaches from present criteria. & $\begin{array}{c}\text { Defense (+) } \\
\text { Aggressive (-) }\end{array}$ & Simons [35] \\
\hline Interactive control & $\begin{array}{l}\text { Principles that make significant of the subgroup to talk, } \\
\text { communicate, educate, and try to find ways. }\end{array}$ & $\begin{array}{l}\text { Defense (-) } \\
\text { Aggressive }(+)\end{array}$ & Simons [36] \\
\hline Financial control intensity & $\begin{array}{l}\text { Accountability for meeting well before performance objectives, } \\
\text { which may or may not be stringent. }\end{array}$ & $\begin{array}{l}\text { Defense (+) } \\
\text { Aggressive (-, } \\
+ \text { ) }\end{array}$ & Simons [37] \\
\hline Variety of criteria & Requirements for effectiveness: restricted to broad & $\begin{array}{l}\text { Defense }(-) \\
\text { Offensive }(+)\end{array}$ & $\begin{array}{l}\text { Merchant [38] } \\
\text { Simons [37] }\end{array}$ \\
\hline \multicolumn{4}{|l|}{ Motivational control scheme } \\
\hline Motivational payments & There is a monetary incentive for motivating staff. & $\begin{array}{l}\text { Defense (-) } \\
\text { Offensive }(+)\end{array}$ & Simons [39] \\
\hline $\begin{array}{l}\text { How to determine } \\
\text { motivational factors }\end{array}$ & $\begin{array}{l}\text { Regarding management evaluations (perception and intellectual) } \\
\text { or present (objective) formulae }\end{array}$ & $\begin{array}{c}\text { Defense (+) } \\
\text { Aggressive (-) }\end{array}$ & $\begin{array}{l}\text { Govindarajan and } \\
\text { Fisher [40] } \\
\text { Simmons [41] }\end{array}$ \\
\hline $\begin{array}{l}\text { Structural control scheme } \\
\text { Type of organizational } \\
\text { structure }\end{array}$ & Human authority, decision-making, and interaction patterns & $\begin{array}{c}\text { Defense (-) } \\
\text { Aggressive }(+)\end{array}$ & Langfield-Smith [42] \\
\hline $\begin{array}{l}\text { Cultural control scheme } \\
\text { Recruitment and selection } \\
\text { control }\end{array}$ & $\begin{array}{l}\text { To match personal views with the interest of the company, use } \\
\text { recruitment, and instructional strategies. }\end{array}$ & $\begin{array}{c}\text { Defense (-) } \\
\text { Aggressive (+) }\end{array}$ & Abernethy [43] \\
\hline
\end{tabular}

transformational leaders' style and management control systems on cooperative and private company management performance. The route analytical framework was utilized to evaluate the data. The Sobel test was employed to assess the control variables. The findings revealed that transformational leadership and three different approaches to developing management control systems could have a direct and indirect positive impact on management efficiency. The Sobel test technique was used to study the role of the mediator variable, which revealed that the robust performance assessment system, reward system, and BSA system all play a mediating role in connection to factors.

According to the concept of appropriateness, no one management control system matches all companies and their textural features. According to this idea, the features of each organization determine the particular properties of an application system. This concept aims to compare organizational features and procedures. In East Java, Indonesia, Riyadi et al. [45] investigated the impact of supply networks and management control systems on production businesses' efficiency and profitability. With rising competition, it is necessary to develop an integrated system in order to achieve corporate profitability. The study's significant result is that businesses should be aware of the social environment produced as part of the supply chain since it can potentially diminish the value of a company's profitability if not built properly and precisely. Dana et al. [46] present an analysis of the literature in management control systems and the intellectual capital accounting method in logistics and how these concepts connect to business performance durability. Intellectual capital is one of the most significant aspects of the value chain in the direction of value creation. Quantifying and presenting intellectual capital allows managers and stakeholders to be successful in running the company. Feder and WeiBenberger [47] investigate the factors that lead to establishing such a CSR-related management controller and the resulting performance impacts of German businesses. It claims that the perceived significance of CSR, stakeholder expectations, and proactiveness of top-level management impact the presence of CSR-related formal and informal regulations, based on legitimacy theory. The article concludes that firms should have a favorable attitude toward CSR and should aggressively integrate comparable features into their internal control systems based on the findings. Companies may also direct their CSR-related actions and create good performance impacts by incorporating CSRrelated features into their management control systems, including formal and informal controls. Owolabi et al. [48] aimed to look at the link between the design and usage of performance measuring innovations and organizational results across Nigerian listed companies. It suggests that utilizing performance measuring technologies in a diagnostic approach creates a bad picture of the client, but this is not the case when used interactively.

\section{Methods and Materials}

Management control systems have been classified in several ways in finance literature. These subcategories are formal and informal controls, experience and control outcomes, and poor financial and nonfinancial regulations $[35,42]$. The contrast between financial and nonfinancial controls has been considered in these several categories, which have been used to investigate the link between the management control system and plan $[49,50]$. As a result, it has been claimed that 
in order to better link management control systems to the present competitive climate, nonfinancial analysis, in addition to short-sighted economic information, is required [51]. Simon utilized controls, diagnosis, and confrontation as a framework for analyzing the differences among financial and nonfinancial management control systems. Identification control has a backward and intraorganizational strategy and is connected with financial management control systems; mutual administration, on the other hand, is linked with nonfinancial management control systems and moves forward externally. In business planning, financial and nonfinancial factors are essential; as a result, the management control system is divided into two main types in this study: financial and nonfinancial. Suppose such an examination allows for a more comprehensive assessment of the management control system's connection in businesses. According to [34], there is a pressing need for research into the nonfinancial aspects of management control systems. Such interactive types of control can improve managers' capacity to foresee and handle unpredictable upcoming scenarios, particularly changing events in a competitive corporate environment [52]. As a result, nonfinancial control is also considered while dealing with these financial investigations.

The following financial management control system aspects have been studied in the literature:
(i) Cost norms
(ii) Deviation evaluation
(iii) Financial management
(iv) Recruitment expenses
(v) Overhead expenses
(vi) Cost-benefit analysis

The following are nonfinancial management control system aspects that have been studied in management control system publications:

(i) Customer appreciation

(ii) Timely and dependable delivery

(iii) Key product activity measures

(iv) Quality

(v) Testing (a continual process of comparing product, service, and assignments and responsibilities to that of rivals)

(vi) Employee-based solutions

(vii) Organizational strategies

Each theoretical model serves as a foundation for research by determining the required factors and their interactions. In other aspects, the conceptual model, also known as a mind map or analytical tool, is ideally used to initiate and conduct research. If predicted, the factors, connections, and interactions between them were evaluated and tested during the study's deployment. As needed, modifications were made, and some of them were decreased or increased. In essence, Porter's triple model is referred to as Porter's generic strategies model, depicted in Figure 1 under three approaches.

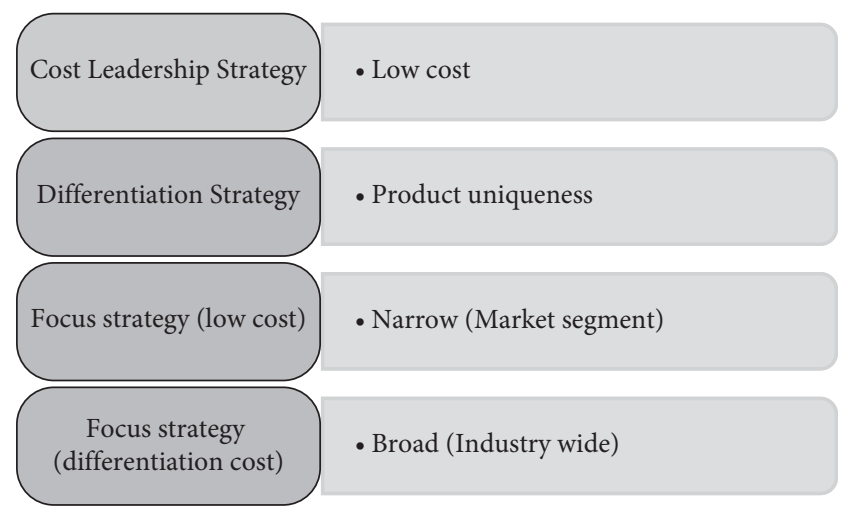

FIgURE 1: Porter's generic three strategies' methods.

The two factors of leadership strategy in this investigation are cost and differentiation, which highlight the strategy of differentiation in attaining higher quality due to the focus strategy's attention on a specific industry area. Wherever feasible, the leadership approach stresses cost minimization. Figure 2 lists the features of each of these different sorts of tactics.

The financial and nonfinancial management control systems, on the other hand, are both relevant when it comes to the strategic plan; thus, the management control system is separated into financial and nonfinancial subgroups in this research since these analyzes allow for a broad assessment of management control system's partnership in businesses. Cost norms, analysis reports, financial management, recruiting cost and variable cost, and overhead evaluation are some of the financial management control system aspects addressed in management control studies. Studies have demonstrated that accepting a specific corporate strategy may enhance performance through timely and dependable delivery, measurements linked to crucial productivity tasks, quality, comparability, employee-based measures, and strategy development $[53,54]$.

Firms seeking a differentiation strategy are less likely to prioritize planning. In contrast, those pursuing a cost leadership approach are more likely to stress capital budgeting assessment [40]. Financial control has resulted in higher performance indicators for a low-cost tactic; however, controls based on nonfinancial or social processes have resulted in higher effectiveness for a differentiation strategy. Differentiation strategy involves nonfinancial elements to inspire innovation and creativity [42] (Porter, 1980). The observations of a recent study back up previous reports that firms with low costs significantly outperformed when they used financial controls and companies with higher differentiation performed much better when they used nonfinancial factors [42]; thus, the nonfinancial management control system is coherent with a differentiation strategy, while the financial management control system is coherent with a differentiation strategy (see Figure 2).

\section{Results and Discussion}

4.1. Data Collection and Questionnaire. Questions regarding management control systems first introduce the notion of 

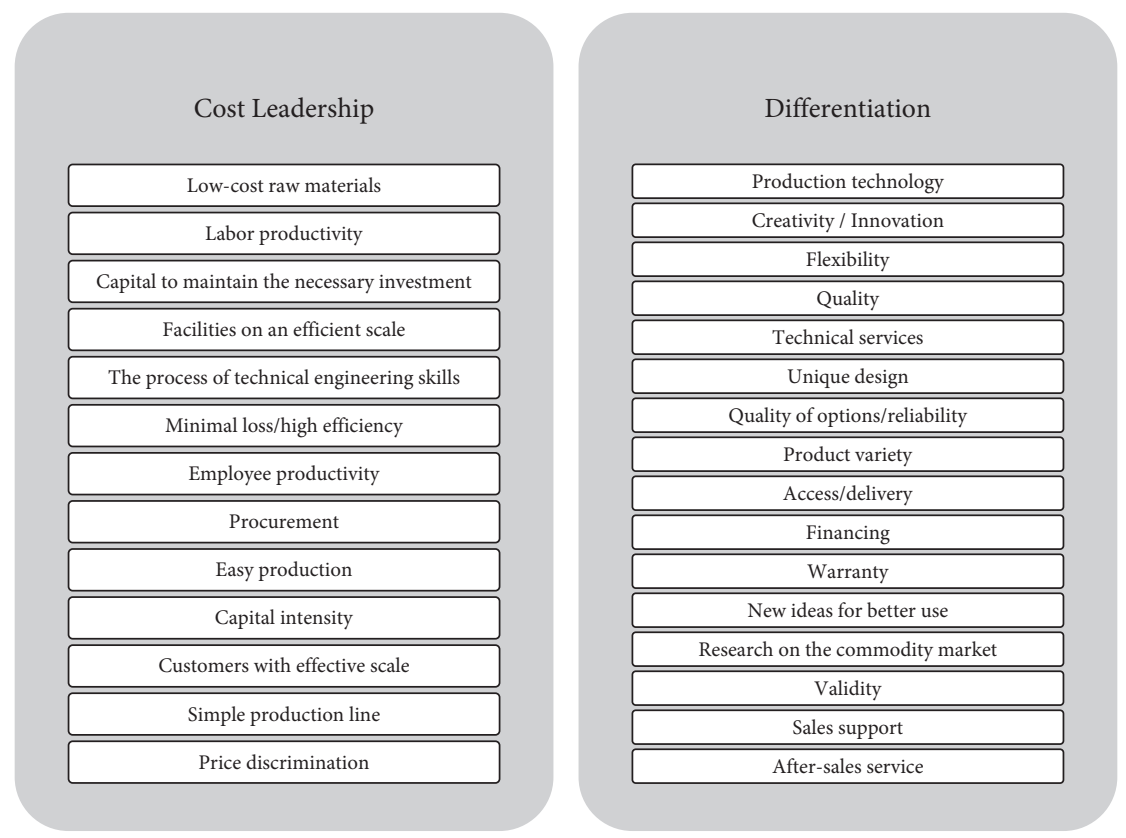

FIgURE 2: Cost leadership and differentiation strategy characteristics.

management control systems to provide responders greater transparency. After that, concerns about management control systems based on financial and nonfinancial aspects are given in two parts. It has 13 nonfinancial factors questions and 16 financial factors questions on a scale of 1 to 9. For an indefinitely large population, Cochran's formula is employed. The statistical population is likely to have a sample size of SD2, which is defined by the degree of dispersion or variation between items and surveys.

4.2. The Presented Method of Financial Assessment of Management Control System. This study is made up of five factors, one of which is the company's plan. First, the company's management control system is also investigated, which is an adjusting factor. Next, the company's productivity is assessed, which is the research's regression coefficient. The management control system is separated into two factors: financial factors-based management control and nonfinancial factors-based management control, using the following four estimation methods (see Figure 3).

All factors are contained in regressors, which are used to verify the specific hypothesis and included as follows:

(1) $\mathrm{P}$ : the performance of the business is equivalent to that of its main rival

(2) CLS: the level to which a company's strategy conforms to a cost-cutting plan

(3) DS: how well a company's strategy aligns with its differentiation strategy

(4) FMCS: financial management control system (FMCS) conformance

(5) NFMCS: nonfinancial control management system (NFMCS) conformance

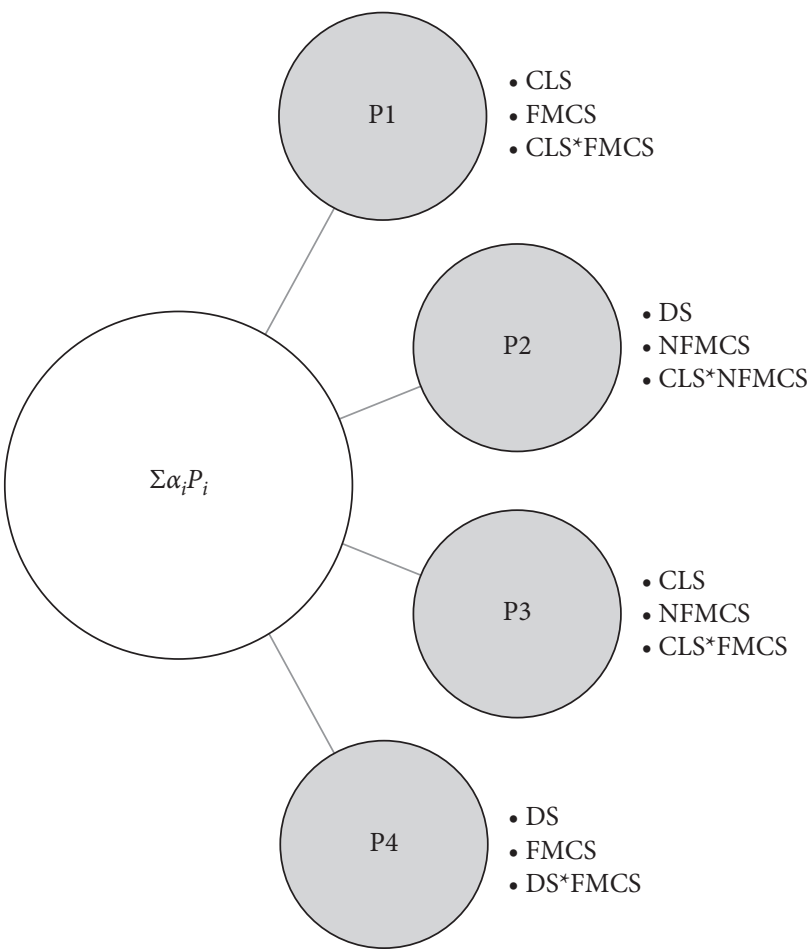

FIgURE 3: The primary equation system of the research.

A questionnaire achieves it with a value ranging from 1 to 9. Other factors in this study and the performance assessment as a dependent variable will serve as independent and control variables, depending on the hypothesis investigated. They will also serve as moderator factors in the case of financial and nonfinancial management control system factors.

Figure 4 shows the DINN that has been provided. It is a type of artificial neural network feedforward technique. It 


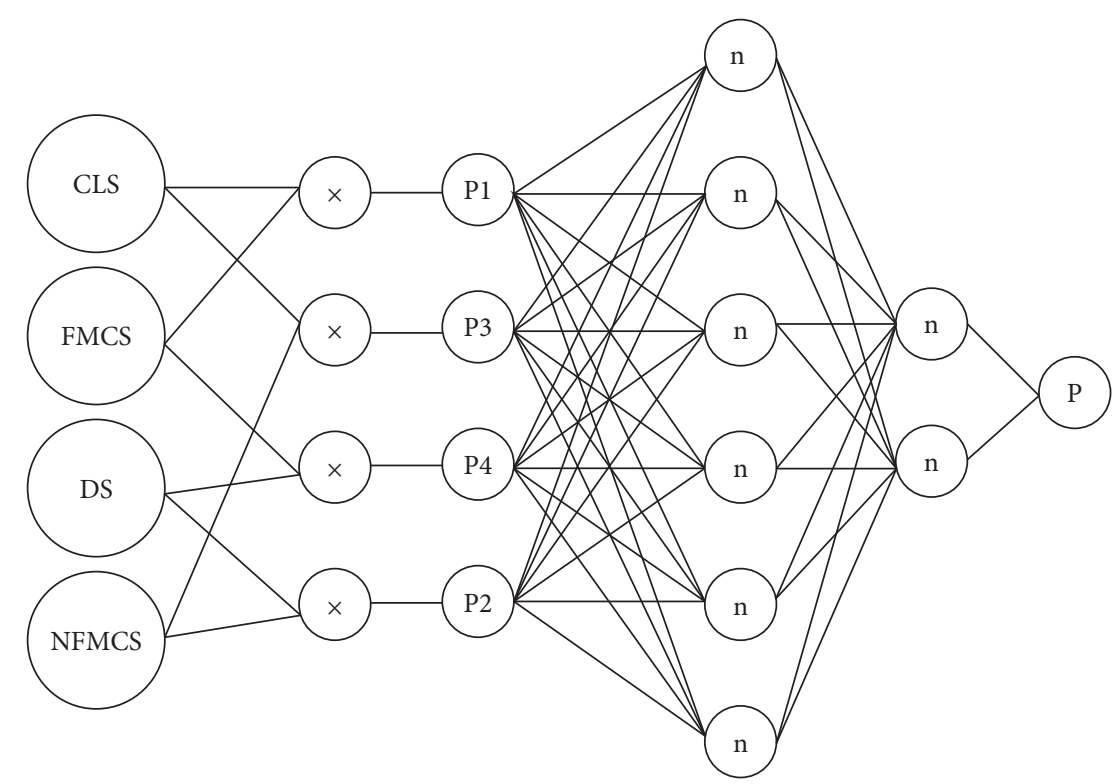

FIGURE 4: The architecture of deep interaction neural network.

has at least five levels, including an input layer that contains the problem's input variables. Based on the governing research problem, the interaction layer is the second layer (see Figure 4). Input and interaction characteristics are included in the third layer, which is the secondary variable layer. The hidden layer of the ANN method includes neurons and weights of each feature in the governing issue in the fourth layer (layers). The last layer is the output layer, which is the goal or dependent variable. Any hidden layers may be reduced to a two-layer input-output system if a DINN has a linear activation function in all neurons; that is, a linear function maps the weighted inputs to the output of each neuron. Some neurons in DINN employ a multilayer perceptron created to simulate the frequency of actual neurons' nerve impulses. The most frequent activation function is sigmoid, which is defined as follows:

$$
\log \operatorname{Sig}\left(v_{i}\right)=\left(1+e^{-v_{i}}\right)^{-1} \text {. }
$$

After each input item is processed, the perceptron learns by adjusting connection weights based on the degree of inaccuracy in the output relative to the predicted result with a learning rate of $10^{-5}$. Backpropagation, a refinement of the least mean squares method in the linear activation functions, is used in supervised methods.

4.3. Results of Prediction Using Presented DINN. The main feature of the study for performance analysis of management control systems is presented in Figure 2. It contains two categories such as cost leadership with 16 features and differentiation including 13 features. The values of each feature are extracted from the questionnaire based on a rate from 1-9. The lower value means the lower importance of each feature. Moreover, it is separated into two financial and nonfinancial features used in the study's classification section. The input and output features of the presented DINN method are as follows (see Figure 1): (i) (x1): MCLS: the mean value of the degree to which a company's strategy adapts to the cost leadership strategy

(ii) (x2): MDS: the mean value of the degree to which a company's strategy adapts to the differentiation strategy

(iii) (x3): FMCS: the mean value of the compliance with the financial management control system

(iv) (x4): NFMCS: the mean value of the compliance with the nonfinancial control management system

(v) (x5): $x 1 . x 3$ : the interaction between $\mathrm{x} 1$ and $\mathrm{x} 3$

(vi) (x6): $\mathrm{x} 1 . \mathrm{x} 4$ : the interaction between $\mathrm{x} 1$ and $\mathrm{x} 4$

(vii) (x7): $\mathrm{x} 2 . \mathrm{x} 3$ : the interaction between $\mathrm{x} 2$ and $\mathrm{x} 3$

(viii) (x8): $\mathrm{x} 2 . \mathrm{x} 4$ : the interaction between $\mathrm{x} 2$ and $\mathrm{x} 4$

(ix) (y) P: the performance of the company is comparable to its leading competitor

In this study, the novel ANN architecture is presented based on the interaction of the input variables. DINN architecture is illustrated in Figure 4. It contains six layers that consist of input layer with 4 variables of $X=\{x 1, \ldots, x 4\}$ and four interaction layers as $\operatorname{Xin}=\{x 5, \ldots, x 8\}$. The third layer is the secondary variable layer includes input and interaction feature $X=\{x 1, \ldots, x 8\}$. The $4^{\text {th }}$ and $5^{\text {th }}$ layers are hidden layers of the DINN approach that includes 20 and 10 neurons, respectively, in the governing architecture. Finally, the last layer is the output layer which is the target or dependent variable of $\mathrm{Y}$.

The results of prediction using the presented DINN method are presented in Figures 5 and 6 . Based on the training process with 7000 epochs, the output results are presented with $93.48 \%$ R-square. Moreover, the absolute mean square error is 0.655 which is illustrated in Figure 5. The output value is connected to the target value with the expression of $Y_{\text {predicted }}=0.86 Y_{\text {Target }}+0.73$. 

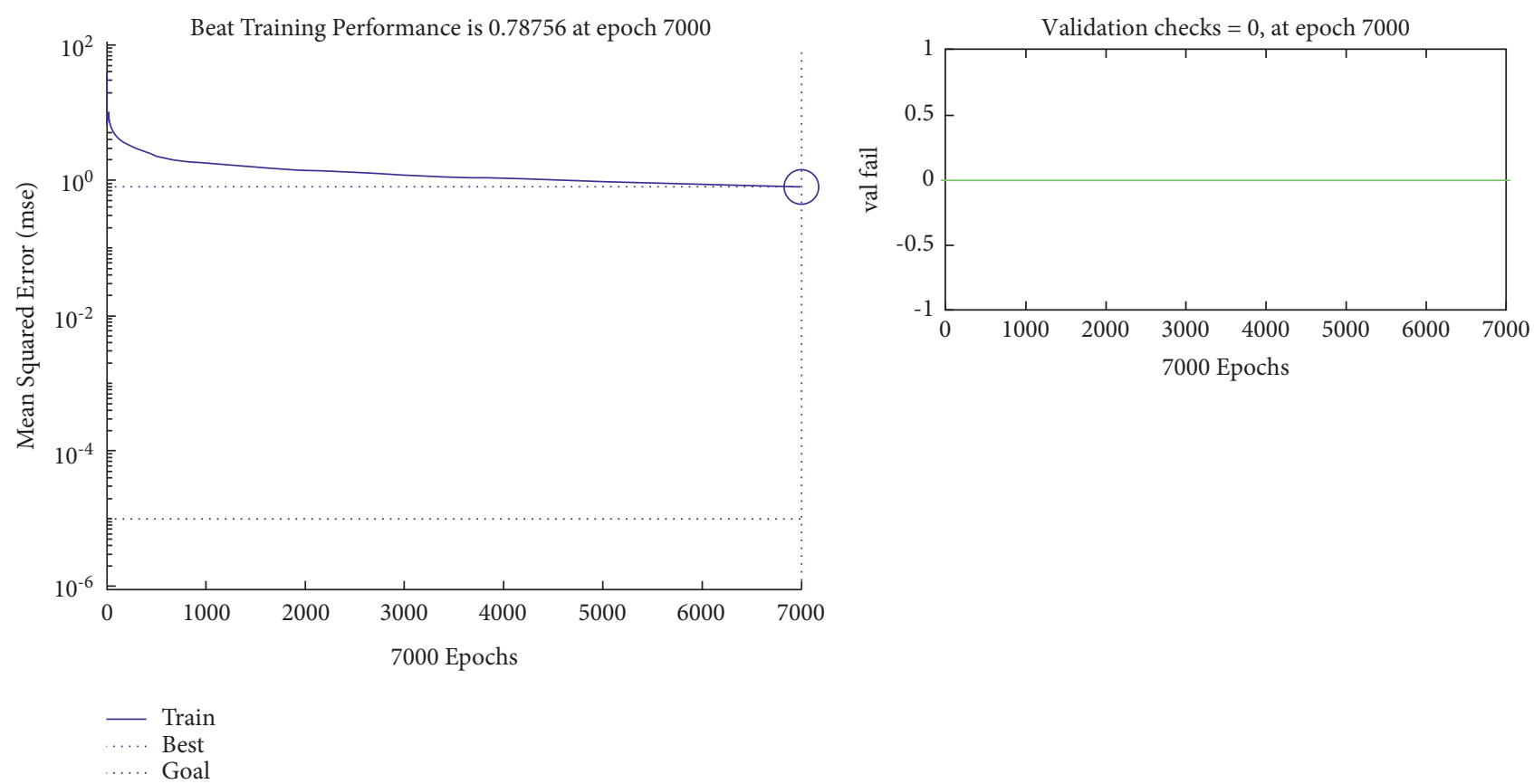

(a)

(b)

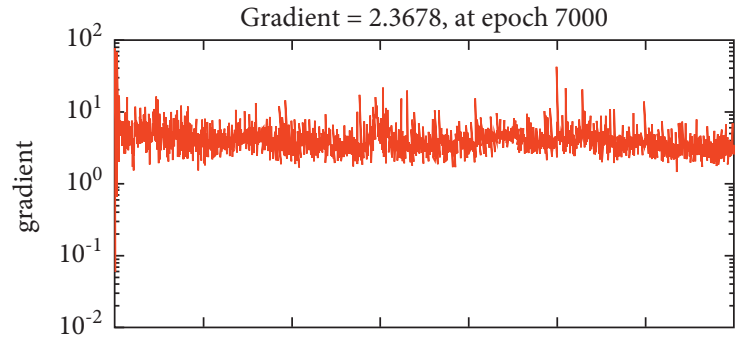

(c)

FIGURE 5: Results of the DINN method for performance prediction. (a) Error value in the training process, (b) failure value in the training process, and (c) the value of the gradient of the target and model value.

4.4. The Results of Classification Using Machine Learning. In this study, participants rate each feature based on a 1-9 importance scale. Finally, it is computed that each one emphasizes of financial criteria of the nonfinancial control system. Based on the input variables of the last section as $X=$ $\{x 1, \ldots x 8\}$ and categorical variable of financial (1) and nonfinancial (0) class, the classification is done. Therefore, this study used five machine learning methods to diagnose and classify the participants' financial and nonfinancial comments. The methods include K-nearest neighbor (KNN), support vector machine (SVM), linear discrimination analysis (LDA), Naïve Bayesian (NB), and decision tree (DT).

The sensitivity and specificity of the two indicators' statistics are utilized to evaluate the binary classification result (duality). The accuracy of the findings of a test that divides the information into these two categories may be measured and described using sensitivity and attribute indicators when the data can be separated into positive and negative groups. Sensitivity refers to the percentage of affirmative situations that are accurately identified as such. The fraction of negative situations that are accurately identified as negative is referred to as specificity.

(i) True positive (TP): the financial comment is detected correctly.

(ii) False positive (FP): the nonfinancial comment is detected with mistakes.

(iii) True negative (TN): the nonfinancial comment is detected correctly.

(iv) False negative (FN): the financial comment is detected with mistakes.

The sensitivity of splitting the number of true-positive instances into the sum of true-positive and false-negative cases in mathematical language is as follows:

$$
\text { sensitivity }=\frac{\mathrm{TP}}{\mathrm{TP}+\mathrm{FN}} \text {. }
$$

Similarly, specificity causes genuine negative cases to be divided into false-positive and true-negative cases. 


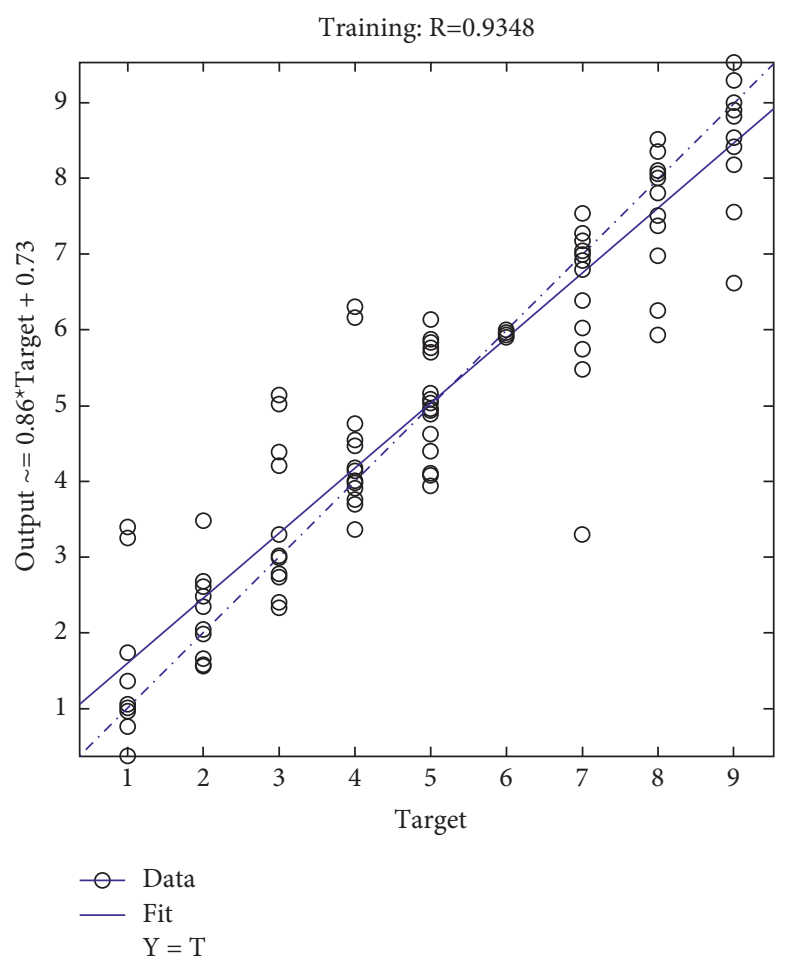

(a)

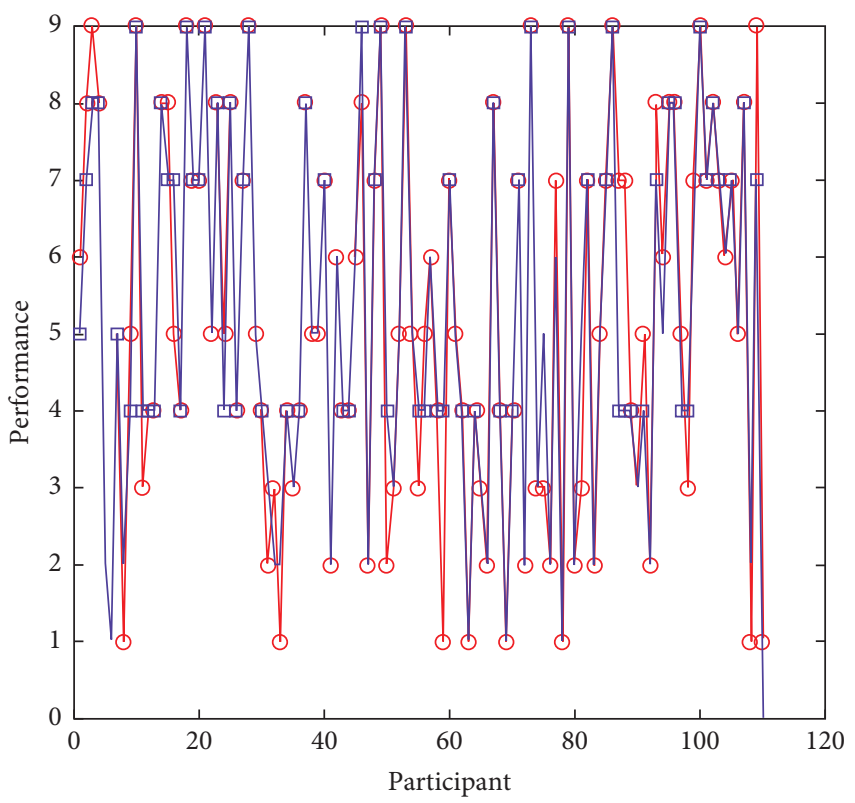

(b)

FIGURE 6: Results of the DINN method for performance prediction. (a) Scatter plot of the performance and (b) the observation plot of the performance of management control system.

$$
\begin{aligned}
\text { specificity } & =\frac{\mathrm{TN}}{\mathrm{TN}+\mathrm{FP}}, \\
\text { precision } & =\frac{\mathrm{TP}}{\mathrm{TP}+\mathrm{FP}}, \\
\text { accuracy } & =\frac{\mathrm{TN}+\mathrm{TP}}{\mathrm{TN}+\mathrm{TN}+\mathrm{FP}+\mathrm{FN}} .
\end{aligned}
$$

The test's nature and kind determine the sensitivity and specificity of a test. The outcome of a test, on the other hand, cannot be evaluated only based on sensitivity and specificity. The confusion matrix is a representation of the operation of algorithms in AI technology. This example is most commonly employed in supervised learning algorithms, although it may also be utilized in unsupervised learning. The anticipated value is shown in each matrix row if each column has a valid (true) case.

The results of confusion matrixes in the classification process are illustrated in Figures 7 and 9. Of 110 participants, 47 emphasized positive (financial) orientation, and 63 focused on negative (nonfinancial) class. Regarding the results of the KNN method in Figure 7, 96.8\% are diagnosed correctly from financial comments. Moreover, from the nonfinancial group, 46 (97.9\%) are located in the negative category. Therefore, the sensitivity and specificity of the KNN are $96.8 \%$ and $97.9 \%$, respectively. Moreover, the precision of the KNN is $98.4 \%$. In other words, from all the detected financial comments, $98.4 \%$ are correct. Finally, the accuracy of the KNN classifier is $97.3 \%$.
Based on the results of the SVM method in Figure 7, from financial comments, $62(98.4 \%)$ are diagnosed correctly. Moreover, from the nonfinancial group, 46 (97.9\%) are located in the negative category. Therefore, the sensitivity and specificity of the SVM are $98.4 \%$ and $97.9 \%$, respectively. Moreover, the precision of the SVM is $98.4 \%$, and the accuracy of the SVM classifier is $98.2 \%$. The false detection has occurred in two of the participants.

Regarding the results of the LDA approach in Figure 8, from the financial participant, 53 (84.1\%) are detected correctly. Also, from the nonfinancial class, 43 (91.5\%) are detected in the nonfinancial group. Therefore, the sensitivity and specificity of the LDA are $84.1 \%$ and $91.5 \%$, respectively. Moreover, the precision of the LDA is $93.0 \%$. In other words, from all the detected financial comments, $93.0 \%$ are correct. Moreover, the accuracy of the LDA classifier is $87.3 \%$. Also, the finding of the NB method is presented in Figure 8; from 63 financial comments, $60(95.2 \%)$ are found correctly. Also, from 47 nonfinancial groups, $44(93.6 \%)$ are located in the negative class. Thus, the sensitivity and specificity of the NB are $95.2 \%$ and 93.6\%, respectively. Moreover, the precision and accuracy of the NB are $95.2 \%$ and $94.5 \%$, respectively. The final method is DT presented in Figure 9 that TP, FP, TN, and FN are 63, 0, 46, and 1, respectively. Therefore, the sensitivity and specificity of the DT are $100 \%$ and $97.9 \%$, respectively. Moreover, the precision of the DT is $98.4 \%$, with an accuracy of $99.1 \%$. The ROC curve is also presented in Figure 10 to illustrate the classifier scores and performance well. The ROC curve is plotted based on the FP rate versus the TP rate. Based on the results, a lower FP rate with a higher TP rate is desirable. 

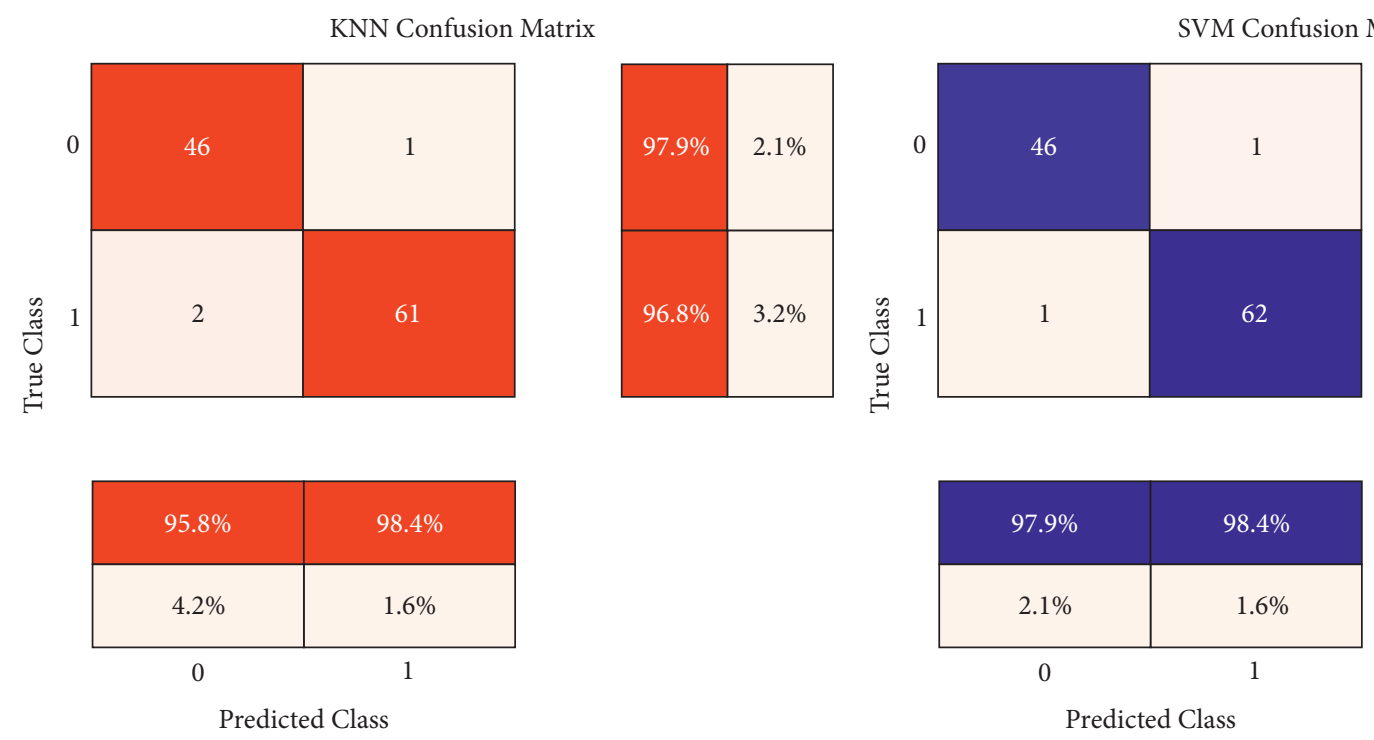

FIgURE 7: Confusion matrix of KNN and SVM methods.
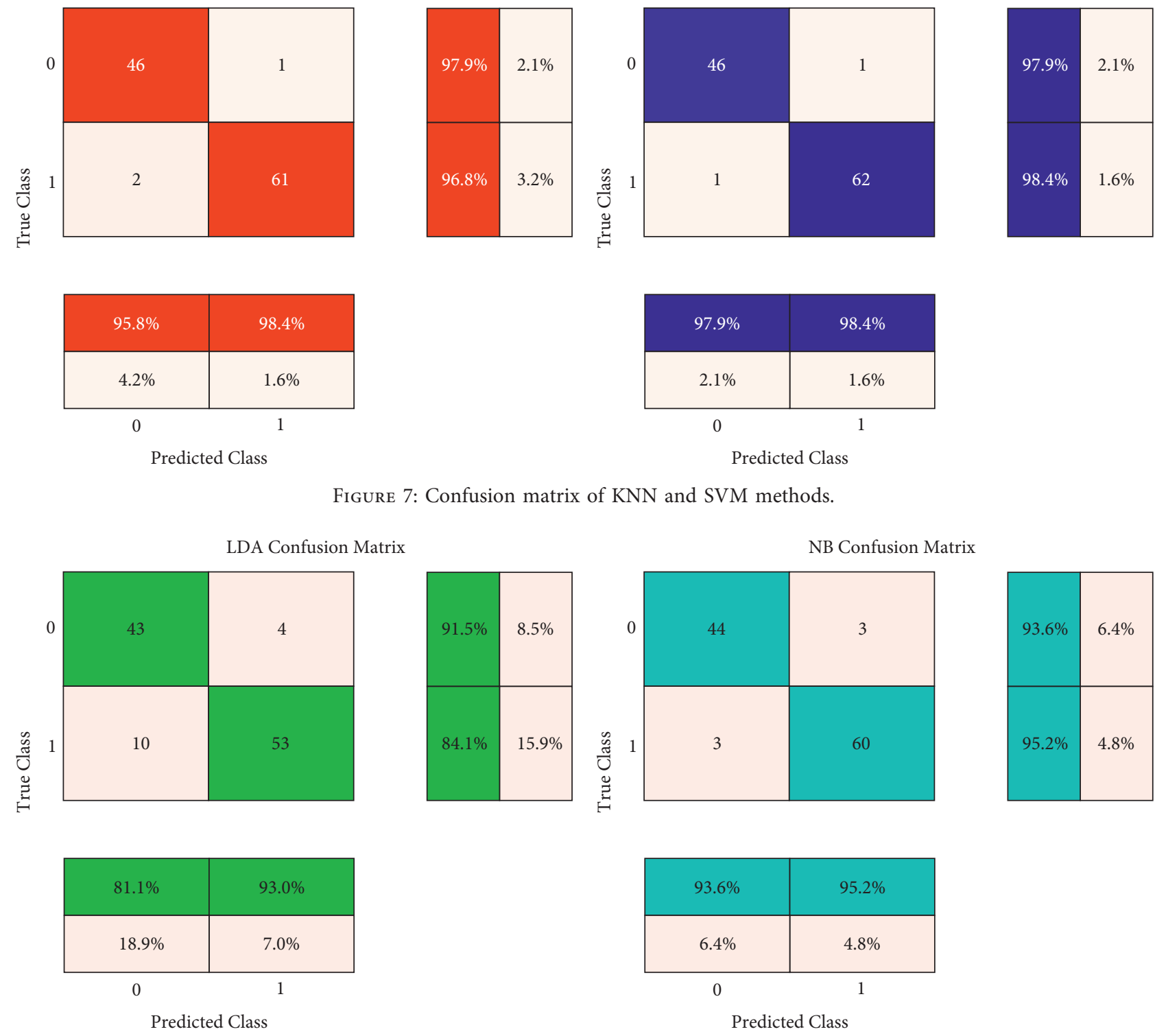

Matrix
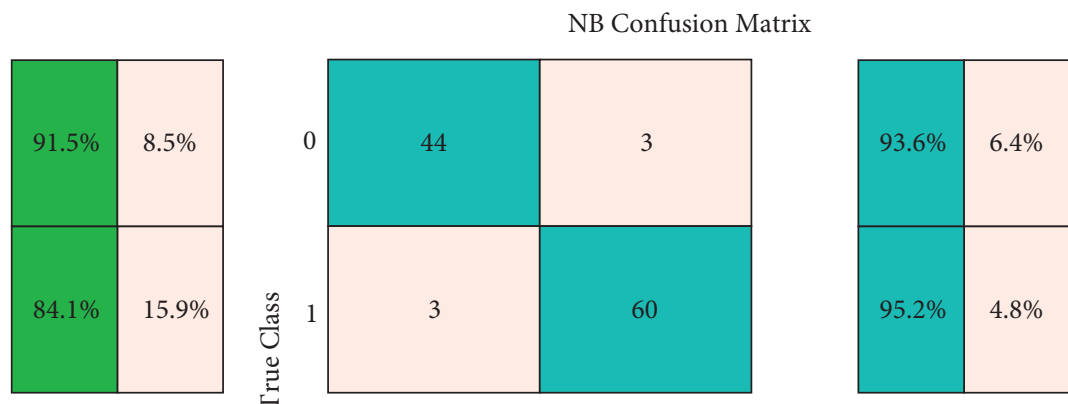

FIgURe 8: Confusion matrix of LDA and NB methods.
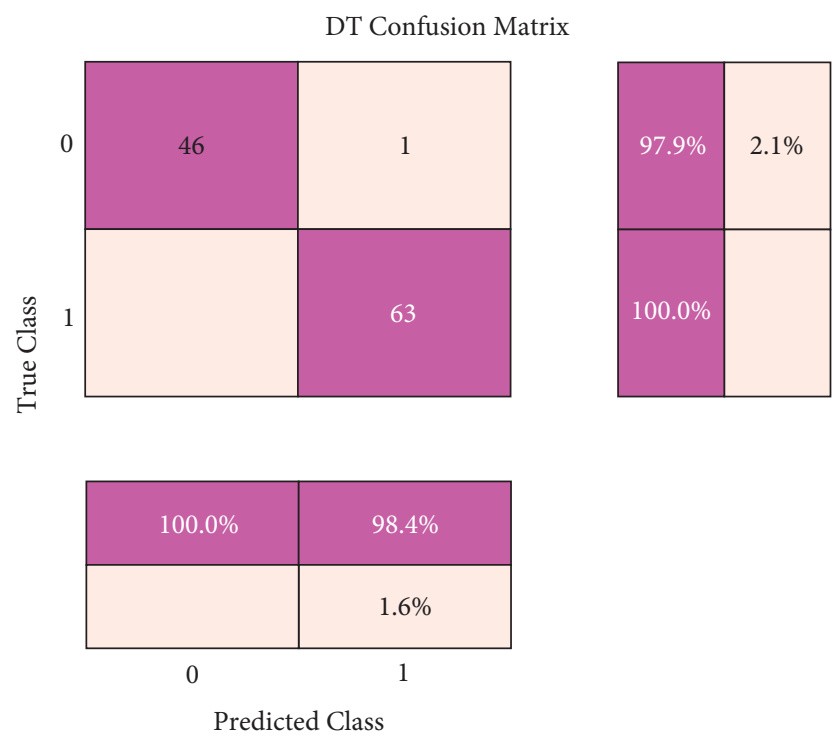

FIGURE 9: Confusion matrix of DT method. 


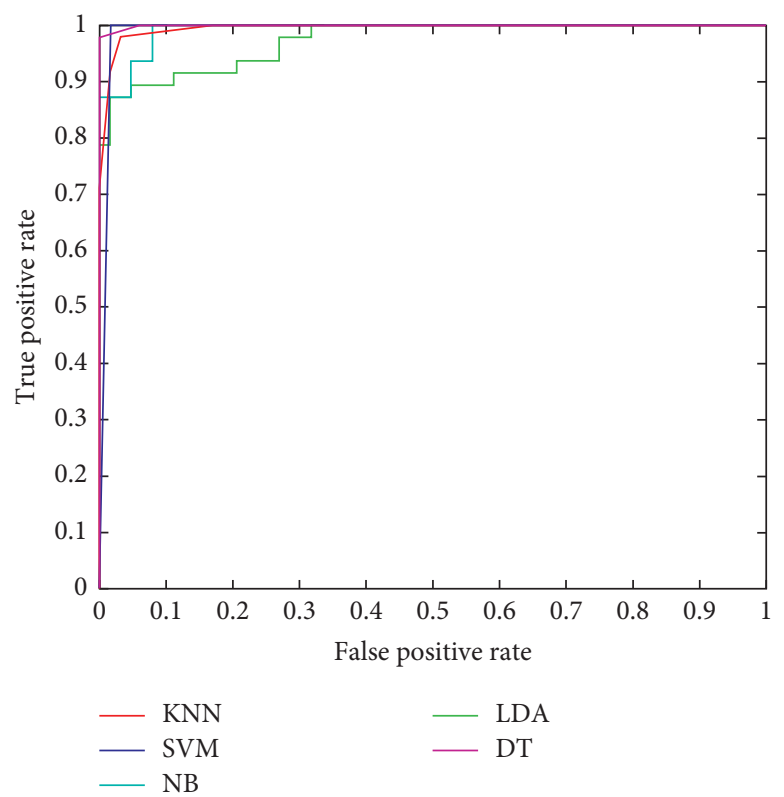

FIgURE 10: The ROC curve for the presented classifiers.

TABLE 2: The comparison between the presented machine learning classifiers.

\begin{tabular}{lccccc}
\hline Method & Sensitivity (\%) & Specificity (\%) & Precision (\%) & AUC (\%) & Accuracy (\%) \\
\hline KNN & 96.8 & 97.9 & 98.4 & 99.46 & 97.3 \\
SVM & 98.4 & 97.9 & 98.4 & 99.16 & 98.2 \\
LDA & 84.1 & 91.5 & 93.0 & 97.26 & 87.3 \\
NB & 95.2 & 93.6 & 95.2 & 99.19 & 94.5 \\
DT & 100 & 97.9 & 98.4 & 99.93 & 99.1 \\
\hline
\end{tabular}

Based on the comparison between the presented machine learning classifiers to detect financial and nonfinancial control management systems in Table 2 , it can be seen that the DT method is presented with higher classification performance values. Based on the results, the higher accuracy belongs to DT with $99.1 \%$ with $100 \%$ sensitivity. Moreover, AUC is the area under the ROC curve to illustrate the performance of the classifiers. The higher value of AUC also belongs to the DT classifier.

\section{Conclusion}

It is essential to evaluate each of the elements in terms of causality to comprehend the efficacy of factors in research with the nature of causal circumstances. Each case will have its own set of criteria for determining the need and sufficiency of causative circumstances. Factors that interact with one another have an interaction impact, increasing or diminishing the desired outcome. The two categories of leadership strategy in this study are cost and differentiation, which highlight the strategy of differentiation in attaining higher quality due to the focus strategy's attention on a specific industry area. Wherever feasible, the leadership approach stresses cost minimization. The financial and nonfinancial management control systems, on the other hand, are both critical when it comes to company strategy; thus, the management control system is split into financial and nonfinancial categories in this study since such analysis allows for an influence society of management control program's connection in industries. The results of prediction using the presented DINN and classification using machine learning methods are as follows. Based on the training process with 7000 epochs, the output results are presented with $93.48 \%$ R-square. Moreover, the mean square error is 0.655. Regarding the results of the KNN method, the sensitivity and specificity of the KNN are $96.8 \%$ and $97.9 \%$, respectively. Moreover, the precision of the $\mathrm{KNN}$ is $98.4 \%$. In other words, from all the detected financial comments, $98.4 \%$ are correct. Finally, the accuracy of the KNN classifier is $97.3 \%$. Moreover, in the SVM from the nonfinancial group, $46(97.9 \%)$ are located in the negative category. From financial comments, $62(98.4 \%)$ are diagnosed correctly. Also, the precision of the LDA is $93.0 \%$. In other words, from all the detected financial comments, $93.0 \%$ are correct. Moreover, the accuracy of the LDA classifier is $87.3 \%$. Furthermore, the sensitivity and specificity of the NB are 95.2\% and 93.6\%, respectively. It can be seen that the DT method is presented with higher classification performance values. Based on the results, the higher accuracy belongs to DT with $99.1 \%$ with $100 \%$ sensitivity in comparison with other classifiers. For the future of the presented work, it can be suggested that the researchers focused on classification 
and performance analysis of the other aspects of the Merchant theory for analysis of the manufactories and production companies.

\section{Data Availability}

Article data were collected through a questionnaire.

\section{Conflicts of Interest}

The authors declare no conflicts of interest.

\section{References}

[1] K. A. Merchant and D. T. Otley, "A review of the literature on control and accountability," Handbook of Management Accounting Research, vol. 2, pp. 785-802, 2007.

[2] K. A. Merchant, Control in Business Organizations, Ballinger, Cambridge, England, 1985.

[3] D. T. Otley, "The contingency theory of management accounting: achievement and prognosis," Accounting, Organizations and Society, vol. 5, no. 4, pp. 413-428, 1980.

[4] T. Malmi and D. A. Brown, "Management control systems as a package-Opportunities, challenges and research directions," Management Accounting Research, vol. 19, no. 4, pp. 287-300, 2008.

[5] D. S. Bedford, T. Malmi, and M. Sandelin, "Management control effectiveness and strategy: an empirical analysis of packages and systems," Accounting, Organizations and Society, vol. 51, pp. 12-28, 2016.

[6] S. He, F. Guo, Q. Zou, and HuiDing, "MRMD2.0: a Python tool for machine learning with feature ranking and reduction," Current Bioinformatics, vol. 15, no. 10, pp. 1213-1221, 2021.

[7] M. Ahmadi and M. Qaisari Hasan Abadi, "A review of using object-orientation properties of $\mathrm{C}++$ for designing expert system in strategic planning," Computer Science Review, vol. 37, Article ID 100282, 2020.

[8] A. Ala, F. E. Alsaadi, M. Ahmadi, and S. Mirjalili, "Optimization of an appointment scheduling problem for healthcare systems based on the quality of fairness service using whale optimization algorithm and NSGA-II," Scientific Reports, vol. 11, no. 1, pp. 19816-19819, 2021.

[9] G. Briganti, M. Scutari, and P. Linkowski, "A machine learning approach to relationships among alexithymia components," Psychiatria Danubina, vol. 32, pp. 180-187, 2020.

[10] D. T. Otley and A. J. Berry, "Control, organisation and accounting," Accounting, Organizations and Society, vol. 5, no. 2, pp. 231-244, 1980.

[11] P. M. Collier, "Entrepreneurial control and the construction of a relevant accounting," Management Accounting Research, vol. 16, no. 3, pp. 321-339, 2005.

[12] Z.-X. Zhang, P. S. Hempel, Y.-L. Han, and D. Tjosvold, "Transactive memory system links work team characteristics and performance," Journal of Applied Psychology, vol. 92, no. 6, pp. 1722-1730, 2007.

[13] K. A. Merchant and W. A. Van der Stede, Management Control Systems: Performance Measurement, Evaluation and Incentives, Pearson Education, London, England, 2007.

[14] M. Ahmadi, "A computational approach to uncovering economic growth factors," Computational Economics, vol. 58, no. 4, pp. 1051-1076, 2021a.

[15] M. Ahmadi, T. Ali, D. Javaheri, A. Masoumian, S. J. Ghoushchi, and Y. Pourasad, "DQRE-SCnet: a novel hybrid approach for selecting users in federated learning with deep-Q-reinforcement learning based on spectral clustering," Journal of King Saud University-Computer and Information Sciences, 2021.

[16] C. Huang, X. Wu, X. Wang, T. He, F. Jiang, and J. Yu, "Exploring the relationships between achievement goals, community identification and online collaborative reflection: a deep learning and bayesian approach," Educational Technology \& Society, vol. 24, no. 3, pp. 210-223, 2021.

[17] X. Wu, W. Zheng, X. Chen, Y. Zhao, T. Yu, and D. Mu, "Improving high-impact bug report prediction with combination of interactive machine learning and active learning," Information and Software Technology, vol. 133, Article ID 106530, 2021.

[18] Y. He, L. Dai, and H. Zhang, "Multi-branch deep residual learning for clustering and beamforming in user-centric network," IEEE Communications Letters, vol. 24, no. 10, pp. 2221-2225, 2020.

[19] M. Ahmadi and R. Taghizadeh, "A gene expression programming model for economy growth using knowledgebased economy indicators: a comparison of GEP model and ARDL bounds testing approach," Journal of Modelling in Management, vol. 14, 2019.

[20] R. Taghizadech and M. Ahmadi, "Statistical and econometrical analysis of knowledge-based economy indicators affecting economic growth in Iran: the new evidence of principal component analysis-tukey and ARDL bound test," Preprint: January, vol. 10, 2019.

[21] F. Liu, G. Zhang, and J. Lu, "Heterogeneous domain adaptation: an unsupervised approach," IEEE Transactions on Neural Networks and Learning Systems, vol. 31, no. 12, pp. 5588-5602, 2020.

[22] J. Dong, Y. Cong, G. Sun, Z. Fang, and Z. Ding, "Where and how to transfer: knowledge aggregation-induced transferability perception for unsupervised domain adaptation," IEEE Transactions on Pattern Analysis and Machine Intelligence, vol. 1, p. 1, 2021.

[23] Y. Zhou, G. Xu, K. Tang, L. Tian, and Y. Sun, "Video coding optimization in AVS2," Information Processing \& Management, vol. 59, no. 2, Article ID 102808, 2022.

[24] S. Lv and F. Song, "Particle swarm intelligence and the evolution of cooperation in the spatial public goods game with punishment," Applied Mathematics and Computation, vol. 412, Article ID 126586, 2022.

[25] A. Sharifi, M. Ahmadi, and A. Ala, "The impact of artificial intelligence and digital style on industry and energy postCOVID-19 pandemic," Environmental Science and Pollution Research, vol. 28, no. 34, pp. 46964-46984, 2021.

[26] N. Ghorbani and A. Korzeniowski, "Adaptive risk hedging for call options under cox-ingersoll-ross interest rates," Journal of Mathematical Finance, vol. 10, no. 4, pp. 697-704, 2020.

[27] N. Ghorbani and A. Korzeniowski, "Call and put option pricing with discrete linear investment strategy," 2021, https:// arxiv.org/ftp/arxiv/papers/2110/2110.04676.pdf.

[28] R. Prasad and K. D. Yadav, "Use of response surface methodology and artificial neural network approach for methylene blue removal by adsorption onto water hyacinth," Water Conservation and Management, vol. 4, no. 2, pp. 83-89, 2021.

[29] N. Ghorbani, Option pricing with investment strategy under stochastic interest rates, The University of Texas at Arlington, $\mathrm{PhD}$ diss., 2021b.

[30] A. Korzeniowski and N. Ghorbani, "Put options with linear investment for hull-white interest rates," Journal of Mathematical Finance, vol. 11, no. 1, pp. 152-162, 2021. 
[31] M. Zhang, Y. Chen, and W. Susilo, "PPO-CPQ: a privacypreserving optimization of clinical pathway query for E-healthcare systems," IEEE Internet of Things Journal, vol. 7, no. 10, pp. 10660-10672, 2020.

[32] M. Ahmadi, S. Jafarzadeh-Ghoushchi, R. Taghizadeh, and A. Sharifi, "Presentation of a new hybrid approach for forecasting economic growth using artificial intelligence approaches," Neural Computing \& Applications, vol. 31, no. 12, pp. 8661-8680, 2019.

[33] J. Artin, V. Amin, M. Ahmadi, S. A. P. Kumar, and A. Sharifi, "Presentation of a novel method for prediction of traffic with climate condition based on ensemble learning of neural architecture search (NAS) and linear regression," Complexity, vol. 2021, Article ID 8500572, 13 pages, 2021.

[34] R. H. Chenhall, "Management control systems design within its organizational context: findings from contingency-based research and directions for the future," Accounting, Organizations and Society, vol. 28, no. 2-3, pp. 127-168, 2003.

[35] R. Simons, "Strategic orientation and top management attention to control systems," Strategic Management Journal, vol. 12, no. 1, pp. 49-62, 1991.

[36] R. Simons, Performance Measurement and Control Systems for Implementing Strategies, Prentice-Hall, Upper Saddle River, 2000.

[37] R. Simons, Levers of Control: How Managers Use Innovative Control Systems to Drive Strategic Renewal, Harvard Business School Press, Boston, Massachusetts, 1995.

[38] K. A. Merchant, "Influences on departmental budgeting: an empirical examination of a contingency model," Accounting, Organizations and Society, vol. 9, no. 3-4, pp. 291-307, 1984.

[39] R. Simons, "How new top managers use control systems as levers of strategic renewal," Strategic Management Journal, vol. 15, no. 3, pp. 169-189, 1994.

[40] V. Govindarajan and J. Fisher, "Strategy, control systems, and resource sharing: effects on business-unit performance," Academy of Management Journal, vol. 33, no. 2, pp. 259-285, 1990.

[41] R. Simons, Levers of Control, Harvard Business School Press, Boston, Massachusetts, 1995.

[42] K. Langfield-Smith, "Management control systems and strategy: a critical review," Accounting, Organizations and Society, vol. 22, no. 2, pp. 207-232, 1997.

[43] M. A. Abernethy and W. F. Chua, "A field study of control system "redesign": the impact of institutional processes on strategic choice," Contemporary Accounting Research, vol. 13, no. 2, pp. 569-606, 1996.

[44] D. Moradi, R. Zandipak, and S. Ghazvineh, "The impact of transformational leadership style and management control system on management performance of Co-operative and private companies in malayer," Co-Operation and Agriculture, vol. 9, no. 33, pp. 15-59, 2020.

[45] S. Riyadi, M. Nugroho, and D. Arif, "The effect of supply network and management control system on the efficiency and profitability of manufacturing companies," Uncertain Supply Chain Management, vol. 9, no. 4, pp. 963-972, 2021.

[46] L.-P. Dana, M. M. Rounaghi, M. Mahdi Rounaghi, and G. Enayati, "Increasing productivity and sustainability of corporate performance by using management control systems and intellectual capital accounting approach," Green Finance, vol. 3, no. 1, pp. 1-14, 2021.

[47] M. Feder and B. E. Weißenberger, "Towards a holistic view of CSR-related management control systems in German companies: determinants and corporate performance effects,"
Journal of Cleaner Production, vol. 294, Article ID 126084, 2021.

[48] F. Owolabi, S. Ajibolade, and U. Uwuigbe, "The design and use of performance measurement innovations and organizational outcomes in Nigerian listed companies," Problems and Perspectives in Management, vol. 19, no. 2, pp. 91-103, 2021.

[49] H. T. Johnson and R. S. Kaplan, Relevance Lost: The Rise and Fall of Management Accounting, Harvard Business School Press, Boston, Massachusetts, 1987.

[50] R. S. Kaplan and D. P. Norton, "The balanced scorecard-measures that drive performance," Harvard Business Review, vol. 70, pp. 71-79, 1992.

[51] R. H. Chenhall, "Integrative strategic performance measurement systems, strategic alignment of manufacturing, learning and strategic outcomes: an exploratory study," Accounting, Organizations and Society, vol. 30, no. 5, pp. 395422, 2005.

[52] S. K. Widener, "An empirical analysis of the levers of control framework," Accounting, Organizations and Society, vol. 32, no. 7-8, pp. 757-788, 2007.

[53] R. Simons, "Accounting control systems and business strategy: an empirical analysis," Accounting, Organizations and Society, vol. 12, no. 4, pp. 357-374, 1987.

[54] R. Simons, "The role of management control systems in creating competitive advantage: new perspectives," Accounting, Organizations and Society, vol. 15, no. 1-2, pp. 127-143, 1990. 